\title{
AROMATASE INHIBITOR FOR OVULATION INDUCTION: A COMPARATIVE STUDY BETWEEN LETROZOLE AND CLOMIPHEN CITRATE IN ANOVULATORY INFERTILE WOMEN
}

\author{
ROKSHANA IVY ${ }^{1}$, AFROZA CHOWDHURY ${ }^{2}$, KULSUM HAQUE ${ }^{3}$, HASMOT ARA 4 \\ Senior Consultant, Department of Obstetrics \& Gynecology, Maternal and Child Health Training Institute, Azimpur, \\ Dhaka $^{1}$, Sonologist, Bangladesh Infertility Management Center, Dhaka ${ }^{2}$, Assistant Professor (Obstetrics \& \\ Gynecology), Begum Khaleda Zia Medical College, Dhaka ${ }^{3}$, Medical Officer (Obstetrics \& Gynecology), Maternal and \\ Child Health Training Institute, Azimpur, Dhaka ${ }^{4}$
}

\begin{abstract}
The study was designed to compare the effectiveness of Letrozole and clomiphen citrate in the treatment of anovulatorv infertility. Thirty patients were selected randomly who had anovulatorv infertility. In letrozole group, fifteen patients got $5-7.5 \mathrm{mg}$ of letrozole orally and in clomiphen citrate group, 100-150 mg of clomiphen citrate was given orally for maximum of six cycles and in both the groups the drugs were started from day $3-7$ of the menstrual cycle. There were no significant differences between the age, duration and type of fertility. But statistically significant increase of follicular development in letrozole group ( $\tilde{n}=0.020$ ). Mean endometrial thickness was $8.33 \pm 1.54$ and $5.36 \pm 1.84$ respectively in letrozole and in clomiphen citrate group $(\tilde{n}=0.048)$. There was no significant difference in ovulation in both the groups but pregnancy was more (33.3\%) with the letrozole group. Letrozole is an effective agent for ovulation induction. It can be used as an alternative to $C C$ as a first-line of treatment for ovulation induction.
\end{abstract}

(Bangladesh J Physiol Pharmacol 2009; 25(1\&2) : 10-12)

\section{INTRODUCTION}

Impaired fertility is thought to affect 10 to $15 \%$ of couples $^{1}$. Ovulation is the prerequisite for pregnancy in female $^{2}$. Clomiphen citrate (CC) has been the first-line method of ovulation induction in couples with anovulatory infertility since its introduction in $1956^{3}$. Clomiphen citrate is a non-steroidal selective estrogen receptor modulator, which acts primarily by binding with estrogen receptors at the hypothalamus ${ }^{4}$. This competitive inhibition results in a perceived drop in drop of circulating estrogen to the hypothalamus, leading to increased gonadotrophin secretion and subsequent induction of ovulation ${ }^{5}$. Approximately $80 \%$ of women ovulate while using clomiphen ${ }^{6}$. But only $40 \%$ of women will achieve pregnancy ${ }^{7}$. This reduced pregnancy rate is disappointingand due to its peripheral antiestrogenic effects, mainly on the quality or quantity of cervical mucus, and endometrial growth and maturation ${ }^{8}$. Long lasting estrogen receptor depletion has been involved in the antiestrogenic mechanism of action of CC. Prolonged estrogen receptor depletion results in the significant

Address of Correspondence: Dr. Rokshana Ivy, Senior Consultant, Department of Obstetrics \& Gynecology, Maternal and Child Health Training Institute, Azimpur, Dhaka thinning of the endometrium, which is dose dependent ${ }^{9}$. It also appears that $\mathrm{CC}$ accumulates in the body because of its long half-life $(2 \text { weeks })^{10}$.

Because of these problems, the concept of aromatase inhibition was proposed as a new method of ovulation induction that could avoid many of the adverse effects of $\mathrm{CC}^{11}$. Aromatase is a microsomal member of the cytochrome P450 hemoprotein-containing enzyme complex superfamily that catalyzes the rate limiting in the production of estrogen. Aromatase converts androstenedion to estrone and testosterone to estradiol $^{12}$. Aromatase activity is present in many tissues, such as the ovaries, the brain, adipose tissue, muscle, liver, and breast, and in malignant breast tumors. The main sources of circulating estrogens are the ovaries in premenopausal women and adipose tissue in post menopausal women ${ }^{13}$.

Letrozole is a third generation selective aromatase inhibitor ${ }^{14}$. It is an aromatase inhibitor that has been used in women with breast cancer ${ }^{15}$. In the late 1990s, Letrozole began to be used to induce ovulation by being administered in the early part of the menstrual cycle ${ }^{16}$. In this study, ovulation was induced in the infertile 
anovulatory women due to polycystic ovarian syndrome by letrozole and clomiphen citrate.

\section{MATERIALS AND METHODS}

The study was conducted in Bangladesh Infertility Management Center, Dhaka, a private infertility care center. The study period was from February 2008 to January 2009. Thirty infertile women of anovulatory polycystic ovarian syndrome (PCOS) were included in the study. The exclusion criteria were the tubal factor infertility, male factor infertility, endometriosis, hyperprolactinaemia and thyroid disorder. Once inclusion and exclusion criteria were met, alternate woman was selected either for letrozole group or for clomiphen citrate group. Before the study informed verbal consent was taken from all women. In letrozole group, 5-7.5 mg of letrozole and in clomiphen citrate group 100-150 mg of clomiphen citrate were given orally for maximum of six cycles and in both the groups the drugs were started from day 3-7 of the menstrual cycle. The main outcome measures were the follicular growth, endometrial thickness, occurrence of ovulation and pregnancy rate.

Transvaginal ultrasounds were performed to document the follicular growth and the endometrial thickness on day 10 of the cycle and whenever necessary. Follicles were considered as mature when they attained the size of $18 \mathrm{~mm}$ or more. Endometrial thickness was measured as the maximal thickness of the endometrial lining in the plane through the central longitudinal axis of the uterine body. The tri-laminar endometrial pattern and the thickness of endometrium, $8 \mathrm{~mm}$ or more were considered satisfactory. When both the follicular growth and the endometrial thickness were satisfactory, 5000 IU HCG injection was given intramuscularly and advised for timed coitus. Ovulation was observed by transvaginal ultrasounds at 48 hours after the HCG injection and by day 21 progesterone. Pregnancy was confirmed by ultrasonography. The results were analyzed statistically by Statistical Program of Social Science (SPSS) version 11.5.

\section{RESULTS}

The age, duration of infertility and the type of infertility, i.e., primary and secondary were similar in both the groups. The follicular diameter was $19.33 \pm 2.55$ and $16.67 \pm 3.33$ in letrozole and in clomiphen groups respectively. The follicular growth was significantly more in letrozole $(p=0.020)$. Endometrial thickness was significantly higher in letrozole group $(p=0.048)$. Ovulation rate was $80 \%$ and $73.3 \%$ in letrozole and in clomiphen groups respectively and showing no significant differences. Pregnancy rate was higher in letrozole group $(p=0.025)$.During the study period, no miscarriage was reported.
Table I

Response to Letrozole and Clomiphen Citrate (c.c)

\begin{tabular}{lccc}
\hline Response & $\begin{array}{c}\text { Letrozole } \\
\mathrm{n}=15\end{array}$ & $\begin{array}{c}\mathrm{CC} \\
\mathrm{n}=15\end{array}$ & $\mathrm{p}$ \\
\hline Follicular diameter & $19.33 \pm 2.55$ & $16.67 \pm 3.33$ & 0.020 \\
in mm at day 12 & & & \\
Endometrial thickness & $8.33 \pm 1.54$ & $5.36 \pm 1.84$ & 0.048 \\
Ovulation & $12(80 \%)$ & $11(73.3 \%)$ & 0.666 \\
Pregnancy & $5(33.3 \%)$ & $1(6.66 \%)$ & 0.025 \\
\hline
\end{tabular}

\section{DISCUSSION}

Many women suffering from infertility, who failed to release an egg each month. This state of chronic anovulation is characterterized by irregular menstrual cycles and may be accompanied by obesity or hirsutism. The condition is known as polycystic ovarian syndrome. The $20-25 \%$ of patients with PCOS patients are "clomiphen resistant"17,18.

Clomiphen citrate is the most commonly prescribed agent for induction of ovulation. Despite high rate of ovulation, pregnancy rate per cycle remain relatively low. Regardless of normal ovulation, $15 \%-50 \%$ of women on clomiphen citrate will develop a thin endometrium ${ }^{19}$ and it is not improved by addition of supplemental estrogen, suggesting that it is a result of estrogen receptor depletion. Both thin endometrium and non-trilaminar pattern of the endometrium at midcycle have been associated with low pregnancy rates and early pregnancy loss. Letrozole induced accumulation of ovarian androstenidion may result in increased expression of FSH receptors. This would result in enhanced sensitivity of the developing follicles to existing $\mathrm{FSH}$.

In this study, the follicular development was significantly more in letrozole group. Stephanie et al ${ }^{19}$ in their study showed no significant difference $(p=0.11)$ in follicular growth between two groups. This may be due to the selection criteria of taking normal ovulating volunteers in their study. However Begum et $\mathrm{al}^{2}$ in their study showed significant increase in follicular development ( $\tilde{n}<0.005$ ) in letrozole group. In their study, perhaps the population was poor responder to clomiphen citrate. The endometrial thickness in letrozole group is significantly higher $(p=0.048)$. Other studies also showed the similar results. This may be the antiestrogenic effect of clomiphen citrate on the endomertium. There was no significant difference in ovulation in both the groups but pregnancy was more (33.3\%) with the letrozole group. However, one study showed $25.93 \%$ pregnancy with letrozole group and no pregnancy with clomiphen citrate group ${ }^{2}$. No miscarriage found during the study period. In 
another couple of studies letrozle was proven to be safe for women and was not a human teratogen, nevertheless clomiphen citrate may result small for gestational age infants ${ }^{14,20}$.

Letrozole is an effective agent for ovulation induction. In clomiphen citrate resistant cases, letrozole should be the drug of choice before proceeding to injectable drugs, which are far more expensive and carry higher risks of multiple pregnancies. It can be used as an alternative to clomiphen citrate as a first-line of treatment for ovulation induction.

\section{REFERENCES}

1. Mohamed FMM, Robert FC. Aromatase Inhibitors in ovulation induction. Seminars in Reproductive Medicine 2004; 22(1): 61-78.

2. Begum MR, Ehsan Q, Anowara B, et al. Role of aromatase inhibitor in ovulation induction in patients with poor response to clomophen citrate. J Obstet Gynaecol 2006; 32(5): 502-506.

3. Wolf LJ. Ovulation induction. Clin Obst Gynecol 2000; 43: 902-915.

4. Kurl RN, Morris ID. Differential depletion of cytoplasmic high affinity estrogen receptors after the in vivo administration of the antiestrogens, clomiphen, MER-25 and tamoxifen. Br J Pharmacol 1978; 62: 487-493.

5. Kerin JF, Liu JH, Phillipou G, et al. Evidence for a hypothalamic site of action of clomiphen citrate in women. J Clin Endocrinol Metab 1985; 61: 265-268.

6. Gorlitsky GA, Kase NG, Speroff L. Ovulation and pregnancy rates with clomiphene citrate. Obstet Gynecol 1978; 51:265-269.

7. Gysler M, March CM, Mishell DR, Bailey EJ. A decade's experience with an individualized clomiphene treatment regimen including its effect on the post coital test. Fertil Steril 1982; 37:161-167.

8. Fritz MA, Holmes RT, Keenan EJ. Effect of clomiphene citrate on endometrial estroged and pragesteron receptor induction in women, Am J Obstet Gynecol 1991; 165:177185.
9. Eden JA, Place J, Carter GD, et al. The effect of clomiphen citrate on follicular phase increase in endometrial thickness and uerine volume. Obstet Gynaecol 1989; 73: 187-190.

10. Okman KT, Kucuk M, Altaner S. Comparison of the effects of Letrozole and clomiphen citrate on ovarian follicles , endometrium and hormone levels in the rat. Fertil Steril 2003; 80: 1330-1332.

11. Antonio $\mathrm{R}$, Julio $\mathrm{H}$, Jose $\mathrm{K}$, et al. Use of letrozole in assisted reproduction: a systematic review and meta-analysis. Human Reproduction Update 2008; 14: 571-582.

12. Cole PA and Robinson $\mathrm{CH}$. Mechanism and inhibition of cytochrome P-450 aromatase. J Med Chem 1990; 33: 29332944.

13. Lonning PE. Aromatase inhibition for breast cancer treatment. Acta Oncol 1996; 35 suppl 5): 38-43.

14. Rachet F, Simmerpal G, Myla M, et al. Fetal safety of letrozole and clomiphene citrate for ovulation induction. J Obstet Gynaecol Can 2007; 2994: 668-671.

15. Pfister CU, Martoni A, Zamzgni C, et al. Effect of age and single versus multiple doses, pharmacokineticsof letrozole (Femara) in breast cancer patients. Biopharm Drug Dispos 2001; 22: 191-7.

16. Mitwally MFM, Casper RF. Review: aromatase inhibitors for ovulation induction. J Clin Endocrinol Metab 2006; 91: 760-71.

17. Hallie B, Raymond K. Infertility treatment for polycystic ovarian syndrome: when clomiphen does not work. Rev $4 / 3 / 2005$

18. Casper RF. Aromatase inhibitors: new experiments or new value? Updates in infertility treatment 2004. Marco Island, Florida (USA)- 22-24 January 2004.

19. Stephanie A, Fisher MD, et al. A randomized double blind comparison of the effects of clomiphen citrate and the aromatase inhibitor on ovulatory function in normal woman. Fertility and Sterility 2002;78:280-285

20. Tulandi T, Martin J, Al-Fadhil, et al. Congenital malformation among 911 newborns conceived after infertility treatment with letrozole or clomiphen citrate. Fertil Steril 2006; 85: 1761-5. 